\title{
La lucha contra la pobreza, un problema internacional
}

La lutte contre la pauvreté, un problème international

Fight against poverty, an international issue

Isabelle Hillenkamp y Jean-Michel Servet

\section{(2) OpenEdition}

Edición electrónica

URL: http://journals.openedition.org/bifea/7624

DOI: $10.4000 /$ bifea. 7624

ISSN: 2076-5827

Editor

Institut Français d'Études Andines

Edición impresa

Fecha de publicación: 1 diciembre 2015

Paginación: 325-341

ISSN: 0303-7495

Referencia electrónica

Isabelle Hillenkamp y Jean-Michel Servet, « La lucha contra la pobreza, un problema internacional », Bulletin de l'Institut français d'études andines [En línea], 44 (3) | 2015, Publicado el 08 diciembre 2015, consultado el 05 noviembre 2020. URL : http://journals.openedition.org/bifea/7624 ; DOI : https:// doi.org/10.4000/bifea.7624

\section{(2) $(\mathcal{Q} \Theta \Theta$}

Les contenus du Bulletin de l'Institut français d'études andines sont mis à disposition selon les termes de la licence Creative Commons Attribution - Pas d'Utilisation Commerciale - Pas de Modification 4.0 International. 


\title{
La lucha contra la pobreza, un problema internacional*
}

\author{
Isabelle Hillenkamp** \\ Jean-Michel Servet***
}

\begin{abstract}
Resumen
El artículo revisa siete décadas de ayuda al desarrollo y de lucha contra la pobreza, entendida primero a través de una comprensión global de los países «pobres» y luego en el contexto de una creciente conciencia de las disparidades entre países y de las desigualdades sociales internas. Se cubren así sucesivamente periodos tan diferentes como los inicios de la Guerra Fría y la descolonización, las grandes décadas del desarrollo de los años 1960 y 1970, bajo la influencia de las ideas keynesianas, hasta la hegemonía del neoliberalismo y la proclamación de los 0 bjetivos de Desarrollo del Milenio en el año 2000. En una última parte, una breve retrospectiva de la historia de la ayuda al desarrollo en Bolivia, del Plan Bohan hasta el actual proceso de cambio, ilustra el encuentro entre las normas globales del desarrollo construidas a nivel internacional y la historia nacional. Esta relectura pone en evidencia la recurrencia de los debates sobre el volumen de la ayuda, su eficacia, sus criterios de selección, los efectos de oportunismo y el mantenimiento en la dependencia de los países en «desarrollo». Plantea preguntas sobre la función de la ayuda al desarrollo en las relaciones internacionales: ¿instrumento eficaz de «lucha contra la pobreza» 0 de control de las amenazas, reales o imaginarias, provenientes de los países pobres y de mantenimiento de la paz y del status quo entre los poderosos?
\end{abstract}

Palabras clave: desarrollo, lucha contra la pobreza, desigualdades, relaciones internacionales, Bolivia

* El presente texto es una versión mejorada y aumentada del que se ha presentado en francés en la página web del CERISCO PE Pauvreté, Centre d'études et de recherches internationales, Sciences Po París, 2012 (http://ceriscope.sciences-po.fr/pauvrete/content/part1/la-lutte-contre-la-pauvrete-unenjeu-international). La traducción del texto al español fue realizada por Sonia Landa N eyra (Perú). La parte del artículo referida al caso de Bolivia es inédita.

** Centro de Estudios en Ciencias Sociales sobre los Mundos Africanos, Americanos y Asiáticos (CESSMA, UMR 245, París), Instituto de Investigación para el Desarrollo (IRD). E-mail: isabelle. hillenkamp@ird.fr

*** Instituto U niversitario de Altos Estudios Internacionales y del Desarrollo (IHEID, Ginebra). E-mail: jean-michel.servet@ graduateinstitute.ch 


\title{
La lutte contre la pauvreté, un problème international
}

\begin{abstract}
Résumé
L'article parcourt sept décennies d'aide au développement et de lutte contre la pauvreté, comprise d'abord à travers une appréhension globale des pays " pauvres » puis une prise de conscience croissante des disparités entre pays et des inégalités sociales internes. Sont couvertes des périodes aussi différentes que les débuts de la guerre froide et de la décolonisation, les grandes décennies du développement des années 1960 et 1970, sous influence des idées keynésiennes, jusqu'à l'hégémonie du néolibéralisme et finalement la proclamation des 0 bjectifs du Millénaire pour le Développement en 2000. Dans une dernière partie, une brève rétrospective de l'histoire de l'aide au développement en Bolivie, du plan Bohan jusqu'à l'actuel Processus de changement, illustre la rencontre entre les normes globales du développement construites au niveau international et l'histoire nationale.

Cette relecture révèle la récurrence des débats sur le volume de l'aide, son efficacité, ses critères de ciblage, les effets d'opportunisme et le maintien dans la dépendance des pays «en développement ». Elle conduit à s'interroger sur la fonction de l'aide au développement dans les relations internationales: instrument performant de "lutte contre la pauvreté » ou bien de contrôle de menaces, réelles ou imaginaires, en provenance des pays pauvres et du maintien de la paix et du statu quo entre puissants?
\end{abstract}

Mots clés : développement, lutte contre la pauvreté, inégalités, relations internationales, Bolivie

\section{Fight against poverty, an international issue}

\begin{abstract}
The article reviews seven decades of development aid and the fight against poverty as perceived first through a global understanding of «poor» countries and then through a growing awareness of the disparities between countries and of the internal social inequalities within them. It covers periods as different as the beginnings of the Cold War and decolonization, the development decades of the 1960s and 70 s under the influence of Keynesian ideas, until the hegemony of neoliberalism and finally the announcement of the Millennium Development Goals in 2000. In the last part of this essay, a brief retrospective of the history of development aid in Bolivia, from the Bohan Plan until the current process of change, illustrates the encounter between global norms of development created at an international level and national history. This exercise highlights the recurrent character of the debates on the volume of aid, its effectiveness, its targeting criteria, the effects of opportunism and the ongoing dependency of «developing» countries. It raises questions about the function of development aid in international relations: is it an effective instrument of «fight against poverty» or an instrument for controlling the threats, whether real or imagined, coming from poor countries and maintaining peace and the status quo between the powerful?
\end{abstract}

Keywords: development, fight against poverty, inequalities, international relations, Bolivia

La cuestión de la pobreza en las relaciones internacionales desde la Segunda Guerra Mundial se reconoce, en un primer momento, a través de los términos empleados para designar globalmente a los países llamados «pobres» o que tienen aún una gran parte de su población viviendo con bajos ingresos; es decir, países atrasados, tercer mundo, periferia, países dependientes, países subdesarrollados, países menos avanzados, o eufemísticamente llamados «en vías de desarrollo»o «en desarrollo». Posteriormente, se reconocen los términos para designar a algunos 
de ellos como «países emergentes». En este sentido, la expresión «bien-estar y desarrollo » aparece a partir del artículo 22 del pacto de la Sociedad de las Naciones del 28 de junio de 1919. Asimismo, los términos «desarrollo» y «subdesarrollo» referentes a las relaciones internacionales, probablemente aparecen en 1942 en un artículo escrito por un funcionario de la $\mathrm{O}$ ficina Internacional del Trabajo.

El vínculo entre pobreza 0 , más exactamente, entre lucha contra la pobreza y relaciones internacionales, para lo que es el origen mismo de las políticas de desarrollo, ha sido mediatizado a partir del célebre punto 4 del discurso de investidura del presidente Harry S. Truman, quien el 20 de enero de 1949 justificó por primera vez a nivel oficial las políticas de ayuda económicas y financieras como alternativas a las relaciones coloniales mantenidas por los países europeos como España, Francia, Portugal y Reino Unido. La retórica de la lucha contra la pobreza para justificar la ayuda continuó durante las siete décadas siguientes. La innovación consistía en afirmar que las desigualdades económicas entre pueblos podían comprometer gravemente la paz (dicho de otro modo, el statu quo entre las potencias) y que los Estados más ricos debían contribuir, incluyendo para su propio interés, al desarrollo de los pueblos supuestamente más desprovistos. Entonces surgen dos palabras: «subdesarrollo» y «ayuda», las cuales se encontrarían en el centro de las relaciones internacionales en el transcurso de las décadas siguientes. El objetivo de estos términos era contribuir al cambio del estado de ánimo en las relaciones internacionales y más precisamente en la actitud de los contribuyentes con respecto a un apoyo necesario hacia los países de bajos ingresos por cabeza. En este contexto, las instituciones internacionales, bajo diversas formas, habían legitimizado su creación, luego, perpetrado su legitimidad.

El presente artículo revisará siete décadas de ayuda al desarrollo y de lucha contra la pobreza, entendida primero a través de una comprensión global de los países «pobres» y luego en el contexto de una creciente conciencia de las disparidades entre países y de las estratificaciones y desigualdades sociales internas. Se cubren así, sucesivamente, periodos tan diferentes como los inicios de la Guerra Fría y de la descolonización, las grandes décadas del desarrollo de los años 1960 y 1970 , bajo la influencia de las ideas keynesianas, hasta la hegemonía del neoliberalismo y la proclamación de los 0 bjetivos de Desarrollo del Milenio en el año 2000, en que los gobiernos y las organizaciones intergubernamentales están comprometidos hasta 2015.

Al releer los discursos y los análisis de cada periodo, se hace evidente la recurrencia de los debates sobre el volumen de la ayuda, su eficacia, sus criterios de selección, los efectos de oportunismo de los países donantes como de los beneficiarios y el mantenimiento en la dependencia de los países en «desarrollo». Esta relectura muestra primero, como lo supone Philip Mader (2015), que el concepto de pobreza no es un hecho objetivo, sino que la pobreza en un momento dado solo puede entenderse a través de las instituciones, las políticas y los instrumentos desplegados para combatirla o pretender combatirla. Mientras termina un periodo estructurado, ideológica y financieramente, en torno a los O bjetivos del Milenio, este historial de siete décadas de ayuda al desarrollo invita 
a moderar el entusiasmo actual de los discursos y de los compromisos a favor de los 0 bjetivos para el Desarrollo Sostenible, propuestos en septiembre de 2015 en la Asamblea General de la O rganización de las Naciones Unidas (O NU) para los próximos quince años y cuyo financiamiento fue aprobado anticipadamente en un encuentro en Addis Abeba en julio de 2015.

Finalmente, esta relectura muestra también el lento proceso de construcción de la ayuda como norma del desarrollo que, por ser global, no es menos contradictoria ni controversial. Al encontrarse con la historia y las fuerzas sociales de cada país, esta norma global produce resultados necesariamente diversos, como lo ilustrará, por último, una breve retrospectiva de siete décadas de ayuda internacional al desarrollo en Bolivia, desde el Plan Bohan hasta el actual proceso de cambio.

\section{LA FABRICACIÓN DEL CO NCEPTO DE SUBDESARRO LLO}

Volvamos a las circunstancias y a los objetivos del discurso de Harry S. Truman, presidente demócrata de los Estados Unidos desde 1945 hasta 1953. El primer punto de su discurso de investidura implicaba un apoyo a la O NU; el punto 2, la continuación del Plan Marshall y el punto 3, la creación de la O rganización del Tratado del Atlántico Norte (OTAN) como órgano común de defensa. El punto 4, que fue preparado por un trabajo de lobbying de su equipo de campaña, aparece como el punto original de la política anunciada por el presidente elegido aquel otoño. Durante su discurso, Harry S. Truman anuncia, en ese cuarto punto, una asistencia a los países llamados «pobres» extendiendo la ayuda más allá de los países de América Latina. Una vasta campaña fue orquestada con los medios de comunicación acerca de la idea del «subdesarrollo». Se trataba de convencer a los contribuyentes estadounidenses de que el apoyo a estos países correspondía no solo a razones humanitarias (que la mentalidad cristiana dominante de los estadounidenses podía aceptar en parte), sino también a los intereses de los Estados Unidos, si es que estos querían evitar la expansión del comunismo. Este periodo constituye el inicio de la Guerra Fría entre los Estados Unidos y la Unión Soviética. Los partidos comunistas progresan notoriamente en Filipinas, China, India, Brasil, Sudán, etc. La solución colonial al estilo europeo parece completamente ineficiente para hacer frente a esta situación. Según las autoridades estadounidenses, esta circunstancia provoca las ideologías marxistas justificando sus luchas revolucionarias y las guerrillas, no solo a través del objetivo final de independencia económica y política fijada por ellas mismas, sino también a través de un apoyo a las fracciones más desheredadas de los pueblos, que supuestamente deben constituir su base social esencial. Para comprender el anticolonialismo norteamericano, es necesario recordar que los Estados U nidos se sienten como una antigua colonia liberada por una lucha armada antibritánica, aun cuando este oculte su ocupación en tierras amerindias y, por otro lado, en territorio mexicano y su anexión; aventuras coloniales tanto como su intervención en Cuba, Puerto Rico y Filipinas que encuentran como pretexto una oposición frente a la potencia colonial española. En adelante, se trata de construir un nuevo orden mundial 
que consolide el sistema capitalista uniendo las minorías étnicas privilegiadas en las cuales apoyarse, a las firmas multinacionales con una acción masiva de las organizaciones internacionales que se convierten en los pilares de la promoción de la ayuda cuya meta directa e indirecta es la pobreza endémica de estos países.

En Europa y, en particular, en el Reino Unido, la cuestión de la ayuda también va a aparecer después del periodo de reconstrucción y de la cuestión de la independencia de las colonias. En el Reino Unido, en otoño de 1950, el Plan de Colombo (The Colombo Plan for Co-operative Economic Development in South and South-East Asia) se implanta para responder a las necesidades de los países asiáticos nuevamente independientes y miembros de la Commonwealth. Para Francia, se trata principalmente de las independencias de Indochina, África Central (subsahariana y del N orte) y M adagascar; así como para Bélgica y los Países Bajos. Vemos aparecer el término en francés «sous-développé (subdesarrollado)» en diferentes contextos: en el informe del profesor Gaston Leduc (1904-1979), Le sous-développement et ses limites (El subdesarrollo y sus límites), presentado en 1952 en el Congreso de Economistas de lengua francesa (donde plantea el problema de la industrialización de los países agrícolas pobres) y, en la obra de Michel Poniatowski (1922-2002), publicada en 1953 con el título L'avenir des pays sous-développés (El devenir de los países subdesarrollados), y en el cual este político ve el futuro con optimismo a través de una estrecha asociación con las metrópolis. Hoy en día, lo más impactante en este enfoque es que los países son considerados como bloques y que las desigualdades entre pobres y ricos dentro de un mismo país son prácticamente ignoradas. Esta visión que opone a países «desarrollados» versus «subdesarrollados» viene acompañada de una denuncia de las tasas de natalidad elevadas como explicación del subdesarrollo y del crecimiento demográfico exponencial de los países pobres como amenaza para los países ricos. Estas constituyen ideas que en algunos países darán lugar a políticas antinatalistas radicales.

En 1950, un grupo de expertos fue nombrado por el secretario general de las Naciones U nidas para especificar las intenciones de la Carta Magna de la O NU en materia de desarrollo. Su informe, publicado en 1951, fue titulado: Measures for the Economic Development of Under-D evelopped Countries. Aquel informe sugiere que los países donantes transfieran a los países en desarrollo aproximadamente 10 millones de dólares por año, es decir 3\% del ingreso nacional combinado de Europa occidental, Australia, Estados Unidos y Canadá en aquel entonces. Los países beneficiarios debían sacar una suma similar de su ahorro nacional. Se calcula que una inversión de 19 millones de dólares aproximadamente (que representa casi el $20 \%$ de los ingresos nacionales de estos países en 1949) debería elevar su ingreso nacional alrededor de 2,5\% por año. Vemos que el 3\% de ayuda sugerida corresponde al porcentaje del PIB consagrado a Europa durante varios años por los Estados Unidos en el Plan Marshall (principalmente en forma de donativo). Antes del Plan Marshall, los Estados Unidos habían tenido la experiencia de la ayuda externa en Filipinas, país que habían ocupado desde 1899, fecha de la derrota española, hasta 1935. 
En los años 1950, el prejuicio de un efecto necesariamente positivo de la ayuda al desarrollo sobre el ingreso y el bienestar de aquellos que la reciben, es compartido incluso por sus adversarios más virulentos. Todavía no está a la orden del día la crítica de izquierda contra la dependencia y sus efectos alienantes. Para dar una idea del estado de ánimo y del vocabulario de los opositores a «la ayuda al desarrollo» dentro de la primera década de formación de las políticas de ayuda al desarrollo, releamos un artículo de Pierre Gaxotte (1895-1982) publicado en Le Figaro del 1 de octubre de 1956. En ese entonces, su autor era editorialista de este gran periódico conservador francés, miembro de la Academia Francesa y considerado por la derecha, un gran intelectual cristiano:

Nos dicen que debemos ayudar a los países subdesarrollados, enviarles capitales, libros y hombres. No dejamos de hacer más que eso desde hace un siglo. En ello perdemos nuestro dinero y nuestros servidores se vuelven rápidamente nuestros enemigos [...] Dejemos descansar a los pueblos atrasados. No perturbemos su pequeña vida. Dejémosle evolucionar a su modo, solos, sin molestar su manera de pensar y de sentir por los aportes de una civilización que les es extranjera, de una técnica que no han inventado y de una ciencia que ellos no han creado. ¿Q ue digo barbaridades...? Es muy posible. Pero la historia está llena de barbaridades. Cuando iba a la escuela primaria, me hacían dar un centavo por semana para salvar a los pobres chinos, se dice, cuyos padres daban a falta de alimento, de comer a los cerdos. ¿Acaso salvé a los pobres chinos? Espero que no, pues cuando crecí los pobres chinos fueron a Dien Bien Phu y mataron a miles de franceses (citado en Père Piquerez, 1956: 1).

Lejos de poner en duda la relación positiva que podría existir idealmente entre el desarrollo por un lado y la ayuda del otro, la exageración de este antiguo admirador respetado por Charles M aurras y por el Mariscal Pétain, la reconforta. Se supone que la ayuda puede tener, en diferentes grados, un efecto que pudiera desencadenar el apoyo al desarrollo, dicho de otro modo, la lucha contra la pobreza. Esto daría fuerza a lo que Pierre Gaxotte considera por naturaleza como enemigos y que las potencias en proceso de desposesión de su herencia colonial tienen todo el interés, según él, de dejar en estado de supuesto retraso.

El informe Measures for the Economic Development of Under-Developped Countries de la ONU inicia en 1951 la publicación de una larga serie de trabajos que cuantifican las necesidades, indican el monto global necesario de la ayuda y el esfuerzo paralelo de los países beneficiarios y analizan las condiciones estructurales previas al desarrollo. Diez años después, John F. Kennedy fomenta el lanzamiento en las Naciones Unidas de la Primera Década del Desarrollo. Este constituye un hermoso programa cuyo objetivo es satisfacer las necesidades esenciales de las poblaciones. O bservemos que el contexto es comparable al de 1948 para lo que es la percepción de un peligro comunista. En este caso, se ve a América Latina como amenazada por ese peligro desde la victoria de la revolución cubana (1959). La Alianza para el Progreso creada en 1961 por los Estados U nidos aporta 20 millones de dólares de ayuda a América Latina con la condición de 
que existan reformas agrarias y fiscales que, excepto Chile, quedarán siendo letra muerta. De ese modo, el término «desarrollo» se instala en el centro del discurso de las organizaciones de las $\mathrm{N}$ aciones U nidas, como las prácticas de ayuda a los países desde entonces llamados PVD o en vías de desarrollo. Se anuncia que esta ayuda probará su eficacia, lo cual permitirá detenerla más adelante.

Con el fin de la colonización, los medios de comunicación conservadores afirman su posición a favor de un repliegue «cartierista», término proveniente del nombre de Raymond Cartier (1904-1975), editorialista del semanario francés Paris Match, el cual en marzo de 1964 consagró varios artículos a atacar vigorosamente la ayuda a los países en desarrollo, sobre todo hacia los Estados africanos. Asimismo, dos gaulistas se volvieron célebres por una ilustración verbal del cartierismo: Raymond Triboulet (1906-2006) con su «La Bretagne en vez que el Dahomey» y Jean Charbonnel (1927-2014), quien fue Secretario de Estado de Relaciones Exteriores encargado de la Cooperación de 1966 a 1967, con «La Corrèze1 ante el Zambèze». Por lo tanto, sería falso imaginar que este tipo de ideas existían solo entre los militantes y los electores de extrema derecha. Los medios llamados progresistas estaban a favor de la cooperación, una cooperación que será criticada inmediatamente después por los que ven en esta ayuda externa una suerte de recolonialización a través de la puesta en dependencia y la orientación política del modo de desarrollo. Esta última crítica no induce la idea de la ineficacia de la ayuda. Son rechazados el objetivo perseguido y la pérdida de independencia que esta induciría. Algunas críticas de izquierda o de derecha afirman que la ayuda no está dirigida hacia los países que tienen mayores necesidades en términos de desarrollo (sino que es distribuida según criterios reprochables); que los efectos de la ayuda son generalmente muy limitados por un costo considerable; que otros medios serían más útiles (la liberación del comercio, de los préstamos a tasas comerciales respetando la supuesta eficacia del mercado o de las inversiones directas por ejemplo); que la limitación de la fuga de los capitales hacia los países ricos o la detención de gastos inútiles serían más apropiados.

\section{LA INSTITUCIONALIZACIÓ N DE LA AYUDA AL DESARRO LLO}

El vínculo entre ayuda y desarrollo ha sido reafirmado inmediatamente después en los grandes informes que concluyen e inician las Décadas de las políticas de desarrollo (Informes Pearson en 1969, Brandt en 1980, etc.). No hay una de esas grandes comisiones que movilizó decenas de expertos reputados que no nos recuerde de una forma u otra la necesidad de la ayuda para luchar contra la pobreza, sus causas, sus secuelas y los efectos, la necesidad de acrecentarla inmediatamente y volverla más eficaz, lo cual presupone que, por naturaleza, la ayuda podría producir sus efectos positivos esperados. 
En 1960, la Asamblea General de las Naciones Unidas adoptó una moción demandante a los países llamados ricos para consagrar el $1 \%$ de su ingreso nacional para la ayuda al desarrollo, propuesta que encontramos durante la Primera Conferencia de las $\mathrm{N}$ aciones U nidas sobre el Comercio y el Desarrollo (CNUCED) de 1964, a través de diversas posiciones de la Iglesia (especialmente católica) así como en numerosas conferencias posteriores, al punto que teniendo en cuenta la distancia entre deseo y realidad, esta iniciativa pueda ser calificada de deseo piadoso. Es revelador del estado actual de las sociedades humanas que la ayuda al desarrollo no se haya vuelto una suerte de «impuesto mundial de solidaridad» para luchar contra la pobreza. Pero esto supondría el paso de relaciones internacionales interestatales hacia un orden mundial supranacional fundado en mecanismos subsidiarios. Con más o menos reticencias, los países de alto nivel de vida aprueban la idea; sin embargo, en general, no aceptan ningún calendario limitante para alcanzar los objetivos fijados de la ayuda.

Con la proliferación de informes de las instituciones especializadas y subsidiarias de la O NU, las prácticas de ayuda por parte de los países que ya no son antiguas potencias coloniales (tales como los estados nórdicos, Alemania y Japón) pasan a tener una dimensión más o menos universal y a adoptar una lengua única para medir el sacrificio del donante y la supuesta ventaja del beneficiario: los porcentajes del producto nacional bruto o del ingreso nacional, dimensiones macroeconómicas nacidas del desarrollo de las contabilidades nacionales promovido por las Naciones U nidas.

Es impresionante volver a leer hoy en día estos informes en los cuales, estadísticas aparte, están siempre presentes los temblores sobre la pobreza, la necesidad demasiado oportunista de combatirla, la amplitud de los medios para movilizarse y su debilidad con respecto a los gastos de los cuales algunos de ellos son además juzgados como fútiles. Las técnicas de intervención pueden evolucionar, pero las creencias perduran (Rist, 2001 [1996]), como las promesas que únicamente comprometen a aquellos que las reciben y a aquellos que aparentan creer.

En 1969, el informe Pearson fue publicado con el título en inglés Partners in Development. Report of the Commission on International Development (Hacia una acción común para el desarrollo del tercer mundo). Su redacción apunta a conocer en qué estado se encuentra el desarrollo y fue confiada por el presidente del Banco M undial, Robert S. Mc Namara, a un antiguo primer ministro canadiense Lester Pearson (1897-1972). Este constata los fracasos e insuficiencias de los veinte años precedentes sin proponer cambios fundamentales. El ex ministro acentúa la integración creciente de estos países en el mercado mundial a través del auge de sus exportaciones. Sugiere que el objetivo de transferencia del $1 \%$ de la riqueza producida por los países llamados ricos hacia los países supuestamente pobres sea alcanzado antes de 1975 y que, antes de 1980, al menos 70\% de esta ayuda, esté compuesta por ayudas públicas. Así, la Segunda Década para el Desarrollo culmina en 1980 con las mismas deficiencias cada vez mejor identificadas y medidas.

La Tercera Década, la de los años 1980, se abre con el Informe del antiguo canciller alemán Willy Brandt, N orth-South. A programme for survival (Norte-Sur: 
un programa de supervivencia). Este corresponde a una toma de consciencia de la extrema diversidad de los países del Sur y de la fuerte interdependencia de las economías a escala planetaria (ya sea que se trate del suministro en materias primas, de productos manufacturados, o de cuestiones monetarias y de financiamiento, lo cual ilustró ampliamente la crisis de 1973). El instigador de la O stpolitik subraya de este modo las interdependencias Norte-Sur, además de las existentes entre Este y 0 este; en resumen, una toma de conciencia que se iniciaba, desde por lo menos hace una década pero que con el informe de Brandt, penetra sin duda en los medios más conservadores.

Algunas críticas con respecto a la naturaleza de la ayuda y a su efecto presumido sobre el desarrollo son, en efecto, reformuladas por los países llamados no alineados desde la conferencia de Bandoeng en 1955, luego por el Grupo de los 77 fundado en 1964 en el marco de la Cnuced y de donde será lanzado el eslogan: Trade, not aid. Estas críticas se elevan fuertemente con la creación de la Organización de Países Exportadores de Petróleo (O PEP) en 1960, más adelante, con la crisis de 1973. Tales críticas culminan con la Declaración relativa a la instauración de un Nuevo Orden Económico Internacional (NOEI) durante la Asamblea General de la ONU del 1 de mayo de 1974. Los países del tercer mundo reivindican su soberanía sobre los recursos naturales, pero también una ayuda financiera poderosa que deberá permitirles modificar su lugar en la división internacional del trabajo. Con motivo de la Séptima sesión extraordinaria de la Asamblea General de las Naciones Unidas de septiembre de 1975, se presenta otro informe independiente, de la Fundación Dag Hammarskjöld, titulado What now? Another Development ( $¿ Q$ ué hacer? 0 tro desarrollo), el cual preconiza un desarrollo fundado en el self-reliance, así como en la reforma del sistema de las Naciones U nidas. Por el contrario, para los países industrializados, la NO El debe ante todo garantizar la estabilidad de los precios de las materias primas, a cambio de otorgar una aceleración de la transferencia de conocimientos tecnológicos y cierto crecimiento de la ayuda pública y privada al desarrollo.

\section{LA LUCHA CONTRA LA PO BREZA EN EL CONTEXTO DEL NEO LIBERALISMO}

El cambio neoliberal que se inicia con la llegada al poder de Margaret Thatcher en el Reino Unido y de Ronald Reagan en los Estados Unidos, desplaza todas aquellas críticas. Además, los años 1980 están marcados por las crisis de las deudas públicas externas de la mayoría de los países en desarrollo, las cuales reconfiguran profundamente sus relaciones con los Estados industrializados. Las instituciones de Bretton Woods, con la instigación de los acreedores públicos reagrupados en el Club de París, conciben entonces planes de ajuste estructural y de estabilización macroeconómica con miras a liberar recursos para el reembolso de la deuda. De ese modo, estas instituciones encuentran, sino una legitimidad, por lo menos un rol de primer plano. La justificación de la ayuda también evoluciona considerablemente. Hasta la fecha, los keynesianos y neokeynesianos veían en la intervención pública 
apoyada por la ayuda externa, una inversión inicial con efecto multiplicador. A partir de ahí, el sector privado se presenta como el actor más eficaz del desarrollo, cuya ayuda debe favorecer las transformaciones institucionales necesarias para la adopción, por parte de los países receptores, de las reglas sacrosantas de la economía de mercado. Sería totalmente erróneo pensar el periodo neoliberal como una regresión de la intervención estatal. Son las formas y los efectos de la misma que cambian profundamente. El Estado es responsable de los intereses de la propiedad privada (en detrimento de los bienes públicos y de los bienes comunes) y por permitir que la competencia sea el mecanismo autorregulador de las economías y de la sociedad en general. Sin un consenso entre la población, los regímenes políticos represivos aparecen totalmente compatibles con el liberalismo económico defendido por los neoliberales. Así, esta ayuda se convierte ante los ojos de numerosos observadores en un nuevo vector de ingerencia en los llamados desde entonces países del Sur, a los cuales ella permite imponer las reformas macroeconómicas e institucionales necesarias para el proyecto neoliberal.

Los años 1990 se abren con la crítica a los desastres sociales causados por estas políticas y por la afirmación en un informe del Unicef de la urgencia de un ajuste estructural «con rostro humano» (Cornia et al., 1987) y de tomar en cuenta el problema de la pobreza (Banco Mundial, 1990). Este interés por lo «social» en general y por la pobreza en particular marca un cambio con respecto al paradigma de los años 1980. En este marco, el Banco Mundial crea la categoría de pobreza «extrema» en relación con las poblaciones que viven con menos del equivalente en paridad de poder adquisitivo de un dólar diario. Pero la afirmación del nuevo dogma de la lucha contra la pobreza no cuestiona absolutamente al de la economía de mercado. La nueva ayuda internacional y las nuevas políticas sociales asociadas supuestamente operan al margen de los mercados o subsanan algunas de sus fallas. La «determinación» de las poblaciones pobres y la inversión en su «capital social» constituyen las nuevas palabras maestras. Estos objetivos son confiados no solo a los gobiernos centrales y locales, sino también a los dispositivos privados de ayuda que operan en parte con fondos públicos como la microfinanza, apoyada por el Consultative Group to Assist the Poor (CGAP), compuesto por treinta agencias de desarrollo públicas y privadas. Paralelamente, el programa de liberalización de los mercados prosigue, acelerándose con la creación de la Organización Mundial del Comercio (OMC) el 1 de enero de 1995. Esta organización internacional extiende las negociaciones iniciadas por el General Agreement on Tariffs and Trade (GATT), sobre todo en el campo de la agricultura con el round de Doha, abierto en 2001 y que afirma la importancia de tomar en cuenta las necesidades de los países en desarrollo «incluyendo la seguridad alimentaria y el desarrollo rural». Recuperando el eslogan Trade, not aid de los países en desarrollo, la O M C afirma que la liberalización les es benéfica, incluyendo a los más pobres de ellos. De este modo, la lucha contra la pobreza se convierte en la cara supuestamente moral del nuevo neoliberalismo mundial. Esta permite designar a un enemigo para combatir la pobreza, naturalizándola y evitando de ese modo cualquier debate político sobre sus causas. Proporciona además a las organizaciones multilaterales una nueva misión y una nueva razón de ser, a menudo bastante alejada de su mandato inicial (Van Parys, 2005). 
Este periodo se caracteriza por la multiplicación de los actores «socios» de los programas de lucha contra la pobreza: los organismos internacionales; los actores públicos, desde el nivel nacional hasta el nivel local, en la medida en que se plieguen a las reglas de buena gobernanza que supuestamente garantizan la eficacia de la ayuda; los mismos pobres, que deben participar en la elaboración o más a menudo, en la ejecución de los programas que les son destinados; las O NG, que supuestamente representan a la sociedad civil; el sector privado, a través de asociaciones público-privadas a nivel local, sobre todo en el sector del agua y de grandes fundaciones con vocación filantrópica. En 1999, el Banco Mundial y el Fondo M onetario Internacional (FMI) sistematizan ese nuevo paradigma a través de los Documentos estratégicos de reducción de la pobreza, que todo país debe elaborar para acceder a los recursos que provienen sobre todo del condonamiento de la deuda pública externa. Estas dos entidades lo integran el año siguiente dentro de los O bjetivos del Milenio para el Desarrollo (O MD), adoptados durante la Cumbre de las Naciones U nidas de septiembre de 2000 y presentados como el nuevo punto de convergencia de los esfuerzos de toda la cooperación bilateral y multilateral para el desarrollo.

\section{DE LOS OMD A LAS NUEVAS AMENAZAS CONTEMPO RÁNEAS}

Los OMD aportan dos novedades que deben ser señaladas. Por un lado, la afirmación del carácter multidimensional y ya no únicamente monetario de la pobreza a través de ocho objetivos importantes, principalmente sobre la salud, la educación, la igualdad de género y el medio ambiente. Sin embargo, la meta principal sigue siendo «reducir a la mitad, entre 1990 y 2015, la proporción de la población cuyo ingreso es inferior a un dólar diario». Por otro lado, se trata de reconocer el carácter universal de la pobreza que toca también a fracciones de la población de los países llamados ricos, haciendo de la pobreza un problema mucho más complejo que el de una simple oposición Norte-Sur.

No obstante, la reafirmación de estos objetivos «antipobreza» interviene luego de una década de baja de una parte del PIB de lospaíses de la O CDE (O rganización para la Cooperación y el Desarrollo Económicos) consagrada a la ayuda pública para el desarrollo. En la conferencia sobre el Financiamiento del Desarrollo de M onterrey en 2002, los países donadores prometieron un nuevo crecimiento de la ayuda, a condición de que se adopten estrategias diferenciadas para los países emergentes y menos avanzados, en función de su capacidad para recibir inversiones. En 2010, el aporte neto de ayuda pública para el desarrollo contabilizado por el Comité de Ayuda al Desarrollo de la OCDE alcanzó un nivel récord de 128,7 millones de dólares. Sin embargo, este aporte, que incluye las condonaciones de la deuda y la ayuda humanitaria, sobre todo la que fue otorgada a Haití por los Estados U nidos después del sismo del 12 de enero de 2010, solo representa el 0,32\% del ingreso nacional bruto acumulado de los países donantes.

Paralelamente, una evaluación detallada del impacto y de los efectos de los recursos empleados permanece detrás de las cámaras que apuntan hacia las 
buenas noticias y las success stories de la lucha contra la pobreza. Si bien el porcentaje de personas viviendo debajo del umbral de pobreza a nivel mundial fue divido por dos entre 1990 y 2015, alcanzándose de esta manera el primero de los ocho OMD, este resultado es principalmente atribuible al crecimiento económico en China e India. A pesar de las controversias sobre las medidas de la pobreza, los expertos concuerdan en afirmar que la incidencia de la pobreza está en lento descenso en África, pero que en razón del crecimiento geográfico, el número absoluto de africanos que viven con menos de un dólar diario está en alza. Según dos expertos del Banco Mundial, Shaohua Chen y Martin Ravallion, este número se habría prácticamente duplicado entre 1981 y 2005 para la parte del continente ubicado al sur del Sahara. Dicho banco concluye en la necesidad de un refuerzo de los recursos y de las medidas de cooperación internacional. Reducir a la mitad el porcentaje de personas cuyos ingresos sean inferiores a 1,25 dólar por día en África subsahariana es parte de la agenda post-O MD de la ONU. Los O MD, tal como han sido durante más de medio siglo la promesa de ayuda, también son, en cierto modo, milenaristas en la medida que anuncian la llegada de una edad de oro luego del esfuerzo consentido. No obstante, la amenaza que haría pesar la persistencia de la pobreza ha cambiado. Ya no se trata como en los años 1960 y 1970 de los movimientos comunistas que alían a obreros y campesinos encarnando el peligro revolucionario. Las guerrillas rurales ya no dan miedo. Por lo tanto, no es sorprendente que ahora pocas personas se preocupen por el combate de los movimientos maoístas naxalistas de los tribal cast y scheduled casts del campesinado indígena. El enemigo que se alimentaría de la miseria endémica, es hoy en día simbolizado por la figura del integrista religioso, en particular islamista, del narcotraficante o del «coyote». Por otro lado, la ayuda internacional, prueba de una prosperidad futura, no es solamente pública, sino que enlista en sus filas al capitalismo filantrópico de las fundaciones, al social business y al impact financing. Este es el precio que debemos pagar por enfrentar la amenaza de un enemigo que sería movido por la pobreza y, por lo tanto, en cierto modo por la envidia y la búsqueda del reconocimiento. Finalmente - esto implica directamente la dimensión internacional-, la amenaza ya no es la presión demográfica sino cada día más lo son los riesgos climáticos, frente a los cuales las poblaciones calificadas de «pobres» se presentan como las más desprovistas.

\section{A MANERA DE CONCLUSIÓN: AYUDA AL DESARRO LLO Y REDUCCIÓN DE LA POBREZA EN BO LIVIA, DE LAS NORMAS GLOBALES A LA HISTORIA NACIO NAL}

Mientras las normas globales de la ayuda al desarrollo pasan por una última metamorfosis con los 17 Objetivos para el Desarrollo Sostenible, siete décadas de aplicación de estas normas a los países «pobres» han dejado sus huellas necesariamente específicas. Bolivia, ubicada en el corazón de la zona de influencia de los Estados U nidos, ilustra el encuentro entre estas normas globales y la historia y las fuerzas sociales a nivel nacional. Tan pronto como en los años 1941-1942, 
una misión encabezada por el oficial Merwin Bohan prepara un plan de desarrollo para Bolivia. Tomando nota de los límites de la economía minera y campesina en el Altiplano, el Plan Bohan se focaliza en la ciudad de Santa Cruz y en la región oriental del país, por ese entonces escasamente poblada. Prevé la modernización y la diversificación de la agricultura, a través de un enfoque científico y técnico, la construcción de infraestructuras en torno a una carretera Santa Cruz-Cochabamba y el desarrollo del sector de los hidrocarburos. Se anuncia una transferencia financiera de los Estados U nidos de 25 millones US \$ de la época y se demanda un aumento de la presión fiscal en Bolivia (Blasier, 1971).

En 1936, la guerra perdida por Bolivia ante Paraguay en el Chaco había firmado el fin del régimen oligárquico y el inicio de una época turbulenta que llevaría al Movimiento Nacional Revolucionario al poder en 1952. Al final de la Guerra del Chaco, la empresa estadounidense Standard Oil Company había sido nacionalizada, llevando a un enfriamiento de las relaciones entre Bolivia y Estados Unidos. En 1942, el Plan Bohan marca un esfuerzo para restablecer estas relaciones, acompañándose, de una indemnización pagada por el gobierno boliviano a la dicha empresa. A nombre del desarrollo, el plan prioriza la región oriental del país, de la cual los Estados Unidos esperan obtener el caucho y la quinina necesarios para su economía de guerra y hacia la cual se supone que los campesinos y mineros de la parte occidental «subdesarrollada» del país migrarían, iniciando la colonización 0 ccidente- 0 riente.

La revolución de 1952, con el sufragio universal, la reforma agraria, la nacionalización de las minas, la creación de la Central Obrera Boliviana y el cogobierno obrero, si bien cambia radicalmente el escenario político, no hace sino reforzar la necesidad de la ayuda al desarrollo para los Estados U nidos, frente a lo que aparece como una amenaza comunista. Mientras tanto, para el joven gobierno revolucionario boliviano, su reconocimiento por la primera potencia mundial de la época y el principal importador de estaño del país es un requisito para su supervivencia. Nace así un pacto singular, donde la afluencia masiva de donaciones y préstamos de la ayuda al desarrollo de los Estados Unidos se utiliza para financiar el déficit alimentario y fiscal del nuevo gobierno boliviano, a cambio de su dependencia económica y de su sumisión a un cierto control político. En este contexto, se aprueba, en 1955, el código Davenport que permite la inversión extranjera en el sector petrolero en condiciones muy generosas. En pocos años, la norteamericana Gulf O il Company se convierte en la empresa líder del sector. A cambio, la ayuda al desarrollo de los Estados U nidos es multiplicado por 5 (Gordon \& Luoma, 2008). Al mismo tiempo, la marcha hacia el O riente se convierte en un elemento clave de la política gubernamental y en 1960, el Plan de Desarrollo Decenal incorpora los principales elementos del Plan Bohan. Las ideas modernizadoras norteamericanas se abren paso dentro del gobierno revolucionario boliviano cuando, en 1957, comienza el pago del servicio de la deuda externa a los Estados Unidos. A principios de los años 1960, el fracaso gradual de la Alianza para el Progreso y el asesinato de John Kennedy constituyen elementos significativos de la caída del Movimiento Nacional Revolucionario, acontecida en 1964 (M esa et al., 2001). 
La toma del poder por las fuerzas armadas constituye una nueva etapa en las relaciones entre Bolivia y Estados Unidos y en las prioridades de la ayuda al desarrollo. El «peligro» comunista no desaparece, pero en general es limitado, desde la guerrilla del Che Guevara en 1966 y 1967, aplastada por los militares bolivianos con la ayuda de expertos estadounidenses, hasta la guerrilla de Teoponte y la revolución universitaria en 1970. En 1969, el general Alfredo O vando declara la Gulf O il Company «contraria a los intereses nacionales» y la nacionaliza, provocando represalias por parte de los Estados Unidos (embargo petrolero y bloqueo de la construcción del gasoducto entre Bolivia y Argentina) hasta la indemnización que se celebrará en 1978. Mientras que la violencia militar se extiende bajo la dictadura del general Hugo Banzer entre 1971 y 1978, el crecimiento económico se acelera gracias al auge del sector gasífero, impulsado por préstamos concedidos por bancos y financiadores internacionales poco preocupados por las capacidades de reembolso de los dictadores locales. De esta época data también la expansión de los cultivos de coca para la producción de cocaína, que se acelera vertiginosamente bajo la dictadura de Luis García M esa, entre 1980 y 1981. Están así generados los dos ingredientes que formarán el meollo de la ayuda al desarrollo y de las relaciones internacionales de Bolivia durante las próximas dos décadas: la deuda pública externa y el narcotráfico.

El retorno a la democracia, en 1982, acontece en un contexto de crisis de la deuda, de hiperinflación y de caída de los precios internacionales de los minerales y de las exportaciones bolivianas. En 1985, el gobierno de U nidad Democrática y Popular cae y abre el camino a la Nueva Política Económica, que encarna los principios de estabilización macroeconómica y de ajuste estructural de la nueva ortodoxia del Consenso de Washington. En Bolivia y en otros países latinoamericanos, la década está «perdida» y la pobreza, que no había sido erradicada en cuatro décadas de «desarrollo» y de ayuda internacional, se extiende de nuevo rápidamente. Entre 1981 y 1989, el ingreso promedio por habitante cae en un $25 \%$, un nivel altísimo en comparación con el promedio latinoamericano de 8,3\% (Dabène, 1999). Mientras tanto, la erradicación de los cultivos de coca y la lucha contra el narcotráfico se convierten en una nueva condición de la ayuda bilateral de los Estados U nidos. A partir de 1986, este país despliega a sus militares en las zonas de producción de coca y se instaura la problemática del «desarrollo alternativo», de la «Coca contra desarrollo» y la amenaza de «descertificar» Bolivia y cortar la ayuda bilateral.

La década de 1990 se abre sobre la toma de conciencia por parte del gobierno ante la urgencia de tomar medidas «sociales». La Descentralización y la Participación Popular ofrecen un nuevo marco para proyectos de «desarrollo local» y «asociaciones público-privadas», de los cuales las ONG, nacionales 0 extranjeras, se vuelven los actores imprescindibles bajo el supuesto de estar atentas a las necesidades de los pobres (Corsino, 1997). Estos proyectos son alimentados por los fondos otorgados a los gobiernos locales en el marco de la descentralización y, en gran parte, por la ayuda multilateral y bilateral, a la cual contribuyen ahora diferentes países europeos, los Estados Unidos y 
Canadá. «El fortalecimiento de la sociedad civil» que se produce a través de estos dispositivos es complementario, y de ninguna manera opuesto, al proyecto neoliberal que se expresa en términos económicos por la continua expansión de la propiedad privada - la Ley de Capitalización en particular- y de los mecanismos de mercado. A partir de 1997, esta lógica se ve reforzada por la adhesión de Bolivia a la Iniciativa para los países pobres muy endeudados, por la cual el Banco Mundial y el Fondo Monetario Internacional ofrecen un alivio de la deuda externa a cambio de la aplicación de una «Estrategia de reducción de la pobreza». Tres Diálogos Nacionales - en 1997, 2000 y 2004- se organizan para desarrollar esta estrategia, convocando a expertos gubernamentales junto con «representantes» de la sociedad civil, avanzando hacia un empoderamiento gradual de estos últimos en el contexto del auge de los movimientos sociales al principio de la década de 2000 (Almagro, 2004).

Desde finales de 2005, el marco de las relaciones internacionales y de la Estrategia de Reducción de la Pobreza ha sido desplazado por la elección de Evo Morales. Criticando al neoliberalismo como continuación del modelo extractivista y de colonización del Estado, ve a las políticas de reducción de la pobreza como un simple vendaje de esos males. A raíz del proceso constituyente que se abre en 2006, se opera un cambio semántico radical en el cual el vocabulario de la economía plural, del Estado plurinacional y del vivir bien se sustituye con el de los imperativos del mercado y de la reducción de la pobreza. En 2008, el Embajador de Estados U nidos y la Agencia Antidrogas norteamericana seguidos, en 2012, por la agencia de ayuda al desarrollo USAID (U nited States Agency for International Development) son expulsados de Bolivia bajo acusación de injerencia política.

Paralelamente, en una coyuntura de boom económico excepcional, impulsada por los altos precios internacionales de los hidrocarburos y de los minerales, el PIB a precios constantes fue multiplicado por más de tres entre 2005 y 2013, y el PIB per cápita en US\$ constantes subió de 1021 en 2005 a 1323 en 2013. El indicio de pobreza moderada cayó de 60 a $43 \%$ durante el mismo periodo y el de pobreza extrema disminuyó de 38 a 21\%. El indicio de desigualdad de Gini también experimentó una disminución notable, de 0,60 en 2015 a 0,47 en 2011. A pesar de las expulsiones de ONG y de agencias de cooperación internacional, la ayuda pública al desarrollo se mantuvo en un nivel relativamente alto en comparación con los otros países de la región - encima de 50 US\$ por habitante y por año- pero ya no representa sino un pequeño monto en comparación con la inversión pública. En 2013, el primer ítem del Comité de Ayuda al Desarrollo (CAD) de la OCDE recibida por Bolivia se refería a las infraestructuras sociales, por algo más de 200 millones de U S\$. El mismo año, la inversión pública atingía 25935 millones BO B (alrededor de 3700 millones de US\$), de los cuales cerca de 18000 millones (2540 millones US\$) se destinaban a las infraestructuras y a los gastos sociales, o sea, cerca de 9 veces más que la ayuda del CAD.

Estas evoluciones reflejan la nueva configuración de la coyuntura internacional - marcada por la inversión de la geografía mundial de la crisis de la deuda externay del modelo económico nacional boliviano, volcado hacia la intervención del 
Estado y la redistribución. A pesar del discurso gubernamental que valoriza la economía comunitaria, la política económica de estos últimos nueve años se focalizó en la creación o consolidación de las empresas públicas, el control de los precios y de las exportaciones, apareciendo de facto cada vez más como una nueva forma de capitalismo de Estado (Wanderley, 2013).

Los instrumentos de redistribución, en particular los bonos Juancito Pinto, Juana Azurduy de Padilla y la Renta Dignidad, a los que se añaden las inversiones en infraestructuras sociales, contribuyen a explicar el retroceso de la pobreza medida por los indicadores monetarios. Sin embargo, aparecen dudas en cuanto a la sostenibilidad de este proceso - más allá del periodo actual de altos precios internacionales- y de los cambios estructurales que induce. Mientras las señales de emergencia de una nueva clase empresarial aymara se multiplican (Tassi et al., 2012), la mejora de las condiciones de vida de las poblaciones históricamente más desfavorecidas - indígenas, campesinas y mujeres en particular- queda por demostrar (Colque et al., 2015). Los indicadores de mortalidad infantil (por encima de 40 por 1000), maternal (cerca de 200 por 100000 niños nacidos vivos) que se mantienen a altos niveles en comparación regional, confirman que el aumento del ingreso disponible no garantiza una mejora rápida ni automática de las condiciones de vida. Diferentes escenarios se dibujan. El de un cambio estructural, graciasa los efectos de arrastre de las inversiones en los sectores público y privado, ampliando progresivamente la base productiva y la demanda de trabajo calificado. Pero también el de una redistribución alimentando el clientelismo político y la corrupción a partir de la extracción continua de las riquezas naturales y que podría llevar a un revolución autoritaria, más que democrática.

\section{Referencias citadas}

ALM AGRO , J. J., 2004 - La Estrategia Boliviana de Reducción de la Pobreza en el contexto del proceso de descentralización. Estudio de caso sobre la economía política de la reducción de la pobreza, 13 pp.; La Paz: Instituto del Banco Mundial.

BANCO MUNDIAL, 1990 - La pauvreté. Rapport sur le développement dans le monde, 1990, XII + 287 pp.; Washington, D. C.

BANCO MUNDIAL, 2001 - Combattre la pauvreté. Rapport sur le développement dans le monde, 2000-2001, XIV + 81 pp.; París: ESKA.

BLASIER, C., 1971 - The United States and the Revolution. In: Beyond the Revolution: Bolivia since 1952 (J. M. Malloy \& R. S. Thorn, eds.): 53-109; Pittsburgh: University of Pittsburgh Press.

BRANDT, W., 1980 - North-South. A programme for survival. Report of the Independent Commission on International Development Issues, 304 pp.; Londres: Pan Books.

COLQ UE, G., URIOSTE, M \& \& EYZAGU IRRE, J. L., 2015 - Marginalización de la agricultura campesina, seguridad y soberanía alimentaria, 147 pp.; La Paz: Fundación Tierra. 
La lucha contra la pobreza, un problema internacional

CO RN IA, A., JO LLY, R. \& STEW ART, F., 1987 - Ajuste con rostro humano. Protección de los grupos vulnerables y promoción del crecimiento, XXIII + 397 pp.; Madrid: UN ICEF, Siglo XXI.

CORSIN O, D., 1997 - La part des ONG dans la coopération internationale. Alternatives Sud, vol. IV, $\mathbf{n .}^{\circ}$ 4: 35-59.

DABÈNE, O., 1999 - L'Amérique latine au XXe siècle, 191 pp.; París: Armand Colin.

FUNDACIÓN DAG HAMMARSKJÖLD, 1975 - What now? Another development. Report on Development and International Cooperation: Prepared on the O ccasion of the Seventh Special Session of the United Nations General Assembly (New York, 1 to 2 September 1975), 128 pp.; U psala.

GORDO N, G. \& LUOMA, A., 2008 - O il and Gas: The Elusive Wealth Beneath Their Feet. In: Dignity and Defiance: Stories from Bolivia's Challenge to Globalization (). Schultz \& M. Crane Draper, eds.): 77-115; California: University of California Press.

LEDUC, G., 1952 - Le sous-développement et ses problèmes : rapport introduction au Congrès des économistes de langue française (mai 1952). Revue d'économie politique: 133-189.

MADER, P., 2015 - The Political Economy of Microfinance. Financialising Poverty, 304 pp.; Londres: Palgrave M acmillan.

MESA, J., GISBERT, T. \& MESA GISBERT, C., 2001 - Historia de Bolivia, XXXVI + 906 pp.; La Paz: Gisbert y Cía.

NACIO NES UNIDAS, 1951 - Measures for the Economic Development of Under-Developed Countries. Report by a group of Experts, v + 108 pp.; Nueva York.

PEARSO N, L. B. , 1969 - Partners in Development. Report of the Commission on International Development, xvi + 399 pp.; New York: Praeger.

PÈRE PIQUEREZ, 1956 - Notes de un passant. L'Impartial (4 de octubre de 1956), año LXXVI, n. ${ }^{\circ}$ 24187: 1-16; La ChauX-de-Fonds.

PONIATO W SKI, M., 1953 - L'avenir des pays sous-développés, 200 pp.

RIST, G., 2001 [1996] - Le développement, histoire d'une croyance occidentale, v + 442 pp.; París: Presses de la Fondation nationale des sciences politiques.

SACHS, J., 2005 - The End of Poverty: Economic Possibilities for O ur Time, xviii + 396 pp.; Nueva York: Penguin Press.

TASSI, N., ARBO NA, J. M., FERRU FINO, G. \& RODRÍGUEZ-CARM O NA, A., 2012 - El desborde económico popular en Bolivia. Comerciantes aymaras en el mundo global. Nueva Sociedad, vol. 241: 93-105.

VAN PARYS, G., 2005 - A quoi servent les pauvres ? A quoi sert la pauvreté ? Q ue faire des pauvres ?, 9 pp.; Bruselas: Centre de formation pour le développement et la solidarité internationale. Disponible en http://www.iteco.be/antipodes/inclusionou-exclusion/Les-nouvelles-strategies

W AN DERLEY, F., 2013 - ¿Q ué pasó con el proceso de cambio en Bolivia? Ideales acertados, medios equivocados, resultados trastrocados. Una lectura de las políticas públicas para la transformación productiva, pluralidad económica e inclusión social en un contexto de bonanza, 245 pp.; La Paz: Postgrado en Ciencias del Desarrollo de la Universidad Mayor de San Andrés, Plural editores. 